\title{
Cajuína e cristalina: as transformações espaciais vistas pelos cronistas que atuaram nos jornais de Teresina entre 1950 e 1970
}

Francisco Alcides do Nascimento UFPI

\section{RESUMO}

Este artigo reflete sobre Teresina (PI), nos meados do século XX, período em que essa capital, num movimento similar ao ocorrido em outras cidades do mesmo porte, passou por múltiplas e variadas intervenções arquitetônicas e espaciais. Esse processo modernizador, entretanto, não foi recebido sem conflito, uma vez que o idealizado embelezamento urbano - preconizado por urbanistas e intelectuais - tropeçava numa realidade configurada por ruas onde se enfileiravam casebres de pau-a-pique cobertos com palha de coco babaçu. Tomaram-se as crônicas publicadas em diários locais como fontes privilegiadas, considerando os cronistas como observadores atentos ao cotidiano da cidade. Palavras-chave: História; Cidade; Teresina; Modernização.

\begin{abstract}
The article is a proposal to reflect upon Teresina city, capital of Piauí, in the mid$20^{\text {th }}$ century, period in which the capital of Piauí, in a similar movement occurred in other cities of the same importance, it should pass by multiple and varied architectural interventions, which they were done with the intention of changing it in the most beautiful city of hinterland. This process of modernization although, shouldn't be received with no conflict, for as much the idealized urban embellishment - proclaimed by urbanists and scholars - stumbled on a reality represented by streets where mud wall hovels lined up covered with babaçu coconut straw. In attempt of capture the mentioned process above, made use of chronicles published in local periodics as privileged sources, for as much the chroniclers were considered as observers more attentive to the daily of the city. They are more attentive than majority of population and, by their performance, with the greatest and the best conditions to reverberate in the city. Making use of chronicles as sources we intended to do an incursion through the frontiers of History and Literature. keywords: Teresina, chronicles; modernization.
\end{abstract}


Este artigo é uma proposta de reflexão sobre Teresina, capital do estado do Piauí, nos meados do século XX, período em que essa cidade, num movimento similar ao ocorrido em outras de mesmo porte, passou por múltiplas e variadas intervenções arquitetônicas realizadas pelo Estado, prioritariamente com o intuito de transformá-la na mais bela cidade do sertão nordestino. ${ }^{1}$ Esse processo modernizador, entretanto, não seria recebido sem conflito, uma vez que o idealizado embelezamento urbano - preconizado por urbanistas e intelectuais - tropeçava numa realidade configurada por ruas onde se enfileiravam casebres de pau-a-pique cobertos com palha de coco babaçu.

O conflito, referido no título deste artigo, nos remete às múltiplas cidades contidas em Teresina, multiplicidade que insiste em ser reduzida ao uno no âmbito dos discursos que dizem a cidade. Neles é privilegiada a cidade projetada, desejada e desejável, expressa tanto pelos administradores quanto, especialmente, pelos cronistas que atuavam nos seus principais jornais, no período recoberto pela pesquisa.

Cronistas são tomados neste artigo como os observadores mais atentos ao cotidiano da cidade e, por sua atuação, com maiores e melhores condições de ecoá-la. Trata-se de cronistas que se aventuraram pelas trilhas da escrita e decidiram compartilhar suas apreensões e desejos, gestados em olhares distintos, com os leitores dos jornais. São cronistas que toda semana tinham o privilégio de entrar em muitas casas, formar opinião e mesmo serem tidos "por filósofo, médico, charlatão, poeta envergonhado, eremita, psicólogo, falsificador, sacerdote".

Manuel Bandeira ${ }^{3}$ reconheceu na crônica um gênero extremamente favorável a seus procedimentos criativos, uma vez que aceita e fornece vários instrumentos para quem a explora, sendo este um dos motivos de sua difícil classificação. Nesse sentido, o cronista tanto pode estar voltado, de modo rigoroso e preciso, para fatos históricos - quando então se aproxima dos cronistas à moda antiga —, quanto pode dirigir o olhar para o cotidiano das cidades modernas, desenvolvendo, neste caso, uma linguagem prosaica e coloquial, em que, às vezes, desnuda-se a mais intensa poesia.

Este $\operatorname{artigo~}^{4}$ encontra, nesta recorrência a Manuel Bandeira, o principal escopo de apropriação da crônica como um vestígio histórico, uma aventura que, aliás, não é nova, já tendo sido assumida antes, no caso brasileiro, por historiadores como Nicolau Sevcenko ${ }^{5}$ e Sidney Chalhoub, ${ }^{6}$ cujas obras, articulando história e literatura, são amplamente conhecidas na historiografia brasileira. Ademais, desenvolve-se o texto na perspectiva de que o espaço físico e as culturas são elementos constitutivos da vida dos moradores da cidade. Verifica-se a relação dos habitantes com as configurações físicas e imaginárias e reflete-se sobre como constroem, ocupam, usam e disputam lugares, 
dando sentido a eles, projetando sonhos, vivendo carências no alinhavar de uma trama de costumes, tradições, crenças, hábitos, códigos, normas, políticas, condições do lugar, rotinas e memórias inscritas no traçado, na paisagem da cidade e no imaginário dos moradores. As crônicas, neste caso, são fontes privilegiadas de informações para o pesquisador.

A cidade de Teresina, no período compreendido entre 1950 e 1970, viveu um processo de transformações econômicas e sociais ligadas diretamente ao modelo econômico proposto pelos governos populistas e militares. Nessa época o governador do estado Helvídio Nunes de Barros ${ }^{7}$ afirma, por exemplo, que a cidade é pequena, pessimamente iluminada, possui um deficiente e precário serviço de abastecimento d'água e não dispõe de asfalto, esgoto sanitário ou sistema de comunicação. Teresina era, assim, o retrato da pobreza e do atraso do Piauí, denunciando a imprensa escrita local até a falta de produtos de primeira necessidade, como a carne e o café.

O cronista Fonseca Duarte, seguindo as 'pegadas' do governador, avalia de forma pessimista o momento vivido pelo Piauí naquela época e acusa o povo de ser, no mínimo, conivente com as mazelas políticas perpetradas no Estado porque "[se trata de] povo desfibrado, sem coragem, sem educação política, permitindo, de braços cruzados, apático e indiferente, que uma malta de aventureiros e espertalhões tripudie sobre a sorte, negando-lhe a economia, condenando-o à fome e à miséria".

É necessário relembrar o lugar social do qual o cronista fala. A crônica discute o momento político experimentado pela sociedade piauiense e teresinense, inclusive pelo próprio cronista, que acusa o Partido Social Democrático (PSD) de ser o responsável pelo quadro de miséria vivenciado, especialmente, pelos segmentos mais pobres do Piauí. Esse mesmo povo havia acabado de eleger um governador ${ }^{9}$ que pertencia aos quadros do Partido Trabalhista Brasileiro (PTB), em coligação com a União Democrática Nacional (UDN).

José Pinheiro de Carvalho ${ }^{10}$ tem opinião oposta à de Fonseca Duarte. Defende que o Piauí não era pobre, mas desconhecido, e por essa razão publicou uma matéria com 16 páginas e aproximadamente cinqüenta fotografias coloridas nas quais apresentava as potencialidades, apesar de, em dado trecho, afirmar que essas potencialidades, relativas ao babaçu e à carnaúba, ainda não haviam sido exploradas de forma adequada. Defendia também as potencialidades do turismo do Piauí, que tinha como exemplo, segundo ele, Sete Cidades.

Para entender o momento que para uns é de crise e para outros é de desconhecimento das potencialidades econômicas e sociais do Piauí, no que afeta Teresina, é necessário que se faça um breve recuo à década de 1940. Nela, Teresina, juntamente com Parnaíba e Floriano, passou a receber um maior 
contingente de migrantes; atraiu inúmeros serviços e consolidou sua função de centro comercial. Raquel Rolnik ${ }^{11}$ propõe a cidade como ímã, e, no caso de Teresina, podemos lembrar que os serviços de educação e saúde já se destacavam desde as primeiras décadas do século XX. A mesma autora diz que a cidade pode ser pensada como mercado e, nesse caso, Teresina começava a disputar com Parnaíba, localizada no litoral norte do estado, a primazia na área comercial do Piauí.

Outro cronista acredita que, em virtude de sua situação geográfica, Teresina está destinada a ser ainda uma grande cidade, uma vez que "ela fica centrada entre dois rios [Parnaíba e Poti], sendo um o maior da Bacia do Nordeste [o Parnaíba], e vai ser importante entroncamento ferroviário de toda a região". ${ }^{12}$ Segundo o mesmo cronista, a cidade tem um crescimento populacional extraordinário, que seria maior não fossem os problemas da água e da luz. Quanto ao abastecimento de energia elétrica, só será resolvido com a construção da Barragem de Boa Esperança, um sonho acalentado por longos anos, mas só concretizado na década de 1970.

Sobre o aspecto urbanístico, o mesmo cronista avalia que Teresina "é uma cidade bonita e que atrai simpatias dos visitantes". Todavia, destaca que a vida noturna da cidade deixa muito a desejar:

cidade de vida noturna quase morta, pouco servida de casas de diversão no centro urbano. Os dois cinemas que possui têm muito a desejar. Não há respeito dentro deles por causa de elementos mal educados que parece que vão ali fazer molecagem e não assistir aos filmes. As gritarias ensurdecedoras e as piadas inconvenientes são comuns em nossos cinemas.

Dois cinemas são insuficientes para nossa capital. Precisamos mais de dois na artéria central da cidade, mas cinemas modernos, confortáveis, com ar refrigerado e mobiliário decente. ${ }^{13}$

As transformações mencionadas determinam olhares diferenciados. A expansão demográfica, por exemplo, provoca o crescimento dos problemas sociais, especialmente aqueles relacionados com a moradia ou com a falta dela. Em 1950 a população total de Teresina era de 90.723 habitantes, mas já na década de 1970 ela tinha saltado para 363.666 habitantes. O censo demográfico de 1980 indica que moravam na cidade 538.294 pessoas. A maioria dessa população era oriunda de pequenas cidades piauienses, mas fundamentalmente da zona rural do Piauí, e também de outros estados do Nordeste. ${ }^{14}$

Nesse sentido, os costumes e práticas dos homens e mulheres que chegam do campo motivam representantes do poder público a se pronunciarem 
em relação à limpeza pública. É o que fez a Prefeitura Municipal de Teresina que, em nota oficial publicada no jornal Estado do Piauí, apontou os esforços para manter a cidade limpa, embora sob o ponto de vista dos administradores municipais a população não ajudasse:

O prefeito vem, ultimamente, envidando todos os esforços no sentido de manter permanentemente limpos os passeios e os leitos das vias públicas.

Nesse sentido, porém, o Serviço de Administração está encontrando sérias dificuldades, para levar a bom êxito essa determinação.

É que, alguns proprietários ou inquilinos menos esclarecidos, ao invés de colocarem o lixo no interior dos prédios, ou em suas entradas, portões ou corredores, em recipientes estanques, põem-no pelas esquinas das ruas, no chão, em flagrante desrespeito às disposições do Código de Postura do Município.

Essa prática causa péssima impressão aos que nos visitam.

O Prefeito espera a cooperação do povo e esclarece que tomará as providências legais contra o abuso. ${ }^{15}$

É, pois, facilmente perceptível que a elite intelectual e política, por meio de seus representantes e com base em saberes divulgados por médicos sanitaristas e urbanistas, responsabiliza os pobres pelas mazelas da capital do Piauí, acusando-os de agirem de forma incivilizada. O foco daqueles saberes está direcionado aos "setores perigosos", uma vez que suas práticas cotidianas não se coadunam com as práticas burguesas.

A nota enfoca outra questão importante: a preocupação dos administradores com o olhar daqueles que visitavam a cidade. Era preciso, então, que os moradores adquirissem hábitos e práticas dos habitantes dos centros urbanos civilizados, que respeitassem as leis municipais. Esse discurso se apóia em saberes da engenharia e da medicina, os quais, além de ajudar na formatação das leis locais, têm a pretensão de educar os corpos.

Outra crônica tem como tema a Praça Saraiva, um dos mais tradicionais logradouros públicos da capital, e historiciza o processo de urbanização, dando conta da arborização realizada por Luis Pires Chaves, prefeito de Teresina de 1931 a 1935. Reporta-se o autor à ocasião do Centenário de Teresina, ${ }^{16}$ ao prefeito João Mendes Olímpio de Melo, que iniciava a urbanização daquele logradouro público e homenageou a Antonio Saraiva, tido como fundador de Teresina, com uma estátua erguida em frente à igreja de Nossa Senhora das Dores, a padroeira do município. O cronista chega até a gestão do prefeito Petrônio Portella, responsável pela pavimentação das ruas limítrofes da praça.

Todo o seu discurso tem como intenção central apoiar o prefeito de Te- 
resina no processo de afastamento de grupos populares que ali trabalhavam com a venda de frutas, garapa e comida preparada sob a sombra dos oitizeiros, uma vez que a Praça Saraiva foi, por muitos anos, o terminal rodoviário interestadual da cidade.

O povo que tudo quer invadir e muitas vezes, abusivamente, fez da Praça Saraiva, há muito tempo, local de mercado, pensões ambulantes, fazendo comida, café, montando garapeiras debaixo das árvores, já começou a ser afastado moderadamente pelo Prefeito Petrônio Portella, que ali já permitiu posto de automóveis, que serve à imensa população flutuante que transita a toda hora nos carros de linhas interiores e do Ceará e Pernambuco. A Praça Saraiva é, enfim, um dos pontos pitorescos da cidade e não se pode encobrir o zelo administrativo por parte do nosso dinâmico Prefeito... ${ }^{17}$

O foco nodal da crônica, mesmo que de forma indireta, é a higienização da praça. Quando, por exemplo, trata dos alimentos que ali são comercializados, destaca as condições precárias das instalações nas quais são produzidos, sob a sombra de árvores. A expressão "invadir, muitas vezes, de forma abusiva" chama a atenção para o fato de que a administração municipal os tolerava, mas havia vozes contrárias à presença dos vendedores ambulantes no logradouro, sendo ainda emblemático lembrar o ato do prefeito que permitiu a instalação de um estacionamento de "automóveis de praça", como eram chamados os carros de aluguel, uma permissão que significava a cobrança de impostos pelo espaço "concedido". Porém, o cronista deixa transparecer que a ocupação do espaço público pelos vendedores ambulantes não passava por nenhum controle do município, daí o afastamento deles "de forma moderada".

Nessa linha de necessidade de higienização da cidade, a Prefeitura de Teresina publica uma nota explicando o recebimento de recursos financeiros do Ministério do Trabalho, Indústria e Comércio, no valor de 7 milhões de cruzeiros, a serem aplicados na eliminação das casas de palha, nas quais morava a maioria da população. O motivo da nota de esclarecimento foram as críticas à administração municipal, formuladas no Jornal do Comércio, na edição de 29 de junho de $1961 .{ }^{18}$ O depósito bancário foi realizado em nome da Fundação Popular Contra a Casa de Palha, cuja administração diz que os recursos estavam sendo empregados para financiar a fabricação de telhas, ou seja, os recursos eram transferidos diretamente para a 'iniciativa privada', sendo os oleiros que assinavam contratos para a fabricação de telhas as quais a Fundação repassava aos consumidores a 'preço de custo'. 
A Fundação está entregando a telha aos requerentes ao preço de custo, posta ao pé da obra ou casa por $\operatorname{Cr} \$ 2.500,00$ (dois mil e quinhentos cruzeiros), para pagamento no prazo estabelecido pelos interessados, enquanto as olarias estão vendendo à vista ao preço de $\mathrm{Cr} \$ 3.000,00$ a Cr\$3.500,00, o milheiro.

Atendendo ao desejo de atendimento, no mais breve espaço de tempo ao maior número de pessoas... ${ }^{19}$

Como se vê o governo municipal, à falta de uma política de construção de casas populares, recebe recursos públicos e os entrega à iniciativa privada, revelando que os limites entre o público e o privado não existem. Aliás, essa sempre foi uma prática dos governantes brasileiros, haja vista o financiamento da cafeicultura com recursos do governo federal, pelo qual se transferia capital dos setores mais pobres da sociedade para os 'barões do café'.

Cronistas apontavam para outras questões não admitidas pelos administradores, como o fez Simplício de Sousa Mendes, em coluna assinada denominada “Televisão", no jornal O Dia.

Agora mesmo, deixa em evidência que o governo municipal de Teresina não dispõe de meios materiais para levar a efeito os melhoramentos de que a Capital necessita.

... o governo atual do Estado entendeu-se com o governo municipal e assinou convênios, no sentido de que a administração estadual realize melhoramentos urbanos, que não estão ao alcance dos recursos municipalistas. O Estado, com excedente dos seus meios orçamentários, executará o Teatro da Praça Marechal Deodoro. ${ }^{20}$

O cronista, provavelmente, não tinha a intenção de denunciar a escassez de recursos do município de Teresina. Pretendia, provavelmente, evidenciar as ações do governo do estado na construção de obras municipais, mas revela acordo entre as duas administrações no sentido de que o governo estadual realizasse obras que, em princípio, eram da alçada municipal. $\mathrm{O}$ fato pode indicar, entre outros aspectos, que as finanças municipais não eram suficientes para atender às demandas da cidade moderna e seus moradores, no caso a construção de um teatro de arena, localizado na Praça Marechal Deodoro, no centro.

Entre 1940 e 1950 Teresina ganha novas áreas. Na zona Norte, o crescimento se deu em direção aos bairros Mafuá, Vila Operária, Vila Militar, Feira de Amostra e Matadouro. Nas proximidades do Centro, isso ocorria nos bairros Cabral e Ilhotas, enquanto na zona Sul, a expansão acontecia em direção aos bairros Piçarra, Vermelha, São Pedro e Tabuleta. ${ }^{21}$ 
Acelera-se assim o processo de deslocamento de parte da população da área urbanizada para fora do centro antigo e da 'cidade-mãe'. As edificações invadiam territórios pouco ou nada preparados para recebê-las, uma vez que os bairros não dispunham de serviço de abastecimento d'água, o serviço de energia elétrica era precário e raras as ruas com calçamento. O aumento da população e a expansão da cidade provocaram o colapso dos sistemas de abastecimento de água e energia elétrica, e o telefone continuou como um artigo de luxo. Sobre a deficiência no abastecimento de energia elétrica e água, $\mathrm{Cu}$ nha e Silva ${ }^{22}$ escreveu que

com o desenvolvimento da cidade de Teresina, cuja população ultrapassa cem mil habitantes, os serviços de luz e água constituem o mais importante dos seus problemas. De vinte anos para cá, tem sido um dos problemas de maior preocupação do governo estadual.

Desejaria ao menos que ele [Deusdedit Melo, presidente da Cepisa], logo de início, fizesse com que a empresa em apreço substituísse o carvão vegetal pelo óleo diésil [ $[$ ic $]$ em nossa velha Usina, pois é até ridículo que numa Capital de Estado como Teresina, se utilize ainda de lenha em sua Usina Elétrica, como se vivêssemos meio século atrás.

Além do mais, é crime inqualificável devastar as nossas matas, crime previsto no Código Florestal. Cortam-se árvores a torto e a direito, e até árvores frutíferas, como, por exemplo, o pequizeiro, para lenha, para combustível de fornalhas. A devastação de matas é delito de lesa-pátria.

O cronista inicia o seu texto com uma palavra que parecia mágica para a 'elite' brasileira e piauiense: desenvolvimento. A idéia de modernização da sociedade atravessa as mentes e corações dos políticos e intelectuais de direita ou de esquerda, de modo que os problemas da cidade consistem em caminhar rumo ao desenvolvimento que tais segmentos tanto desejavam. É esse desenvolvimento que provoca em Cunha e Silva a preocupação com o meio ambiente, a exemplo das matas ciliares que cobriam as margens dos rios Parnaíba e Poti, devastadas com a retirada de madeira para abastecer as fornalhas da usina fornecedora de energia elétrica para Teresina. O cronista não admite que a capital do estado ainda empregue a lenha como combustível, uma prática por ele considerada 'velha'.

Não se pode esquecer de que o país vivia a euforia da construção de Brasília, traduzida como início de uma era modernizante no Brasil. Juscelino Kubitschek, o presidente de sonhos fáusticos, parecia ter contagiado alguns segmentos da sociedade brasileira com o slogan de governo de fazer o Brasil 
crescer "cinqüenta anos em cinco". Essa euforia com o progresso, discurso construído no governo de Kubitschek, chega ao Piauí, e Teresina é então vista como porta de entrada para esses novos tempos, daí que, em meados da década de 1950, por iniciativa do governo do estado, inicia-se uma tentativa de modernização da máquina administrativa, com a criação da Comissão de Desenvolvimento do Estado, que tinha por objetivo pensar o desenvolvimento econômico do Piauí a médio e longo prazos. No final da mesma década foram criadas algumas empresas de economia mista, merecendo destaque: Frigoríficos do Piauí S.A. (Fripisa), Centrais Elétricas do Piauí S.A. (Cepisa), Agroindústria do Piauí S.A. (Agripisa), Telecomunicações do Piauí S.A. (Telepisa) e Águas e Esgotos do Piauí S.A. (Agespisa). É dessa mesma época a transformação do Banco Agrícola do Piauí em Banco do Estado do Piauí S.A.

Outras ações são empreendidas no sentido de colocar o Piauí no caminho do desenvolvimento, segundo a visão dos atores sociais que atuavam em Teresina. É desse mesmo período a criação da Federação das Indústrias do Estado do Piauí (Fiepi), em 1954. Em meados do ano seguinte foi instituída a Associação Industrial do Piauí (AIP); em 1965 é instalada uma de empresa chamada de Fomento Industrial do Piauí (Fominpi), a qual, algum tempo depois, passaria a chamar-se Companhia de Desenvolvimento Industrial do Piauí (Codipi). A sociedade vê-se, assim, imbuída da necessidade de implantar ferramentas que pudessem ajudar na construção de um novo Piauí, modificando-se a infra-estrutura básica do estado na área de energia elétrica, abastecimento de água e transportes.

prosseguem com ritmo intenso os trabalhos do nosso aeroporto que, segundo palavra oficial, em outubro deste ano, estará pronto e entregue ao tráfego dos mais pesados aviões.

Já está sendo espalhado o asfalto, bem assim adiantadas as bases da grande pista, superior a mil metros de extensão.

A Comarca trabalha com segurança e eficiência para dotar-nos de um grande campo de pouso à altura da capital piauiense, no setor aéreo de cargas e passageiros.

O presidente Jânio Quadros dissera aos piauienses que lhes daria em breve tempo um aeroporto, à capital de seu Estado, e agora se confirma a firmeza da palavra presidencial. ${ }^{23}$

A pavimentação do campo de pouso de Teresina era mais uma ferramenta que permitiria a visita de turistas. Deve-se lembrar que um burocrata da 
Prefeitura de Teresina, em nota pública, manifesta a preocupação com o olhar "daqueles que nos visitam".

Até o final da década de 1950, a cidade se expandiu para o norte e para o sul, mas eis que atravessou o rio Poti, com a construção do primeiro vão da ponte de concreto armado entre a principal avenida da cidade, a Frei Serafim, e a BR-343, rodovia que liga Teresina a Parnaíba. Antes disso, aquela área era ocupada principalmente por chácaras, utilizadas por seus proprietários nos finais de semana. Iracilde Moura Fé comenta essa expansão para a zona Leste, seguida das palavras de Arimatéa Tito Filho:

na década de 1960, foi construída uma pista para corrida de cavalos, embrião do Jóckei Club do Piauí, bem como foram abertos os primeiros loteamentos residenciais do bairro ... As corridas de cavalos se transformaram em atividades de lazer de determinado segmento social da cidade, esta é uma das razões para que a região passe a ser interpretada como área de moradia dos ricos, a ser símbolo de status social e econômico, ficando toda a região conhecida por zona do Jóquei Clube. ${ }^{24}$

Aqui seguirás pela esquerda - para que atinjas a zona militar, a estação da estrada de ferro, a Avenida Frei Serafim - e poderás seguir pela esquerda, até que encontres o Poti e alcances bairros novos - o do Jóckei Clube e o de São Cristóvão, nos quais habita uma pequena burguesia quase classe média. ${ }^{25}$

As mudanças nos modos de vida, as novas exigências de conforto, as inovações de consumo e lazer engendraram uma expansão do território da cidade, em detrimento do centro antigo, que perde habitantes. Com efeito, no início da década de 1970 foi instalada a Universidade Federal do Piauí, após o Jóquei Clube, em direção ao nordeste da cidade, hoje bairro Ininga, fato que leva à publicação de matéria no jornal Estado do Piauí, ${ }^{26}$ na qual um representante do governo afirma que:

é com satisfação que digo que o Ministro Jarbas Passarinho cumpriu o que prometeu: o professor Élcio Uchoa Saraiva, decano da UNB, PHD e formado pela Universidade de Wisconsin, o qual fará, com sua inteligência, uma juventude de apenas 29 anos e sua extraordinária equipe técnica, da Universidade do Piauí a melhor Universidade do Nordeste. ${ }^{27}$

Percebe-se que o articulista deposita uma fé absoluta na ciência, acreditando que a universidade que se implantava no Piauí deveria transformar-se na melhor do Nordeste porque era constituída por cientistas de várias áreas 
das ciências humanas. É, aliás, desse mesmo período a montagem de um projeto que visava, com o apoio da Universidade Federal do Piauí, promover o desenvolvimento do Estado:

Na mesma ordem de idéias, o Governador Alberto Silva fala do Projeto Piauí, um projeto de desenvolvimento apoiado na própria Universidade do Piauí, o qual será efetivado sob a direção do antropologista Prof. João Ribeiro Moreira.

Esse cientista contará com a colaboração de vinte e cinco técnicos de diversas especialidades: Informática, Economia, Sociologia, Estatística, Psicologia e outros. Durante 3 meses essa equipe fará o diagnóstico da problemática local e apontará o caminho a seguir. ${ }^{28}$

Alguns acontecimentos são recebidos pela imprensa como sinal dos novos tempos, destacando-se como exemplo a inauguração de uma fábrica de refrigerantes: "Hoje pelas 16 horas na Avenida Perimetral S/N, no Bairro Buenos Aires nesta capital, será solenemente inaugurada a Fábrica de Coca-Cola da conceituada firma Carlos Henrique Aragão Indústria e Comércio Ltda.”. ${ }^{29}$

Data também desse período a promulgação do Plano Diretor da Prefeitura Municipal, estabelecendo, por exemplo, uma área mínima para os lotes dos bairros da zona Leste, superior à dos bairros mais antigos da cidade. Estabelece também que o recuo para a construção de edificações seria maior, atraindo a população das camadas média e alta da sociedade teresinense. Sobre a expansão espacial da cidade, Arimatéa Tito Filho comenta:

Muitos dizem que Teresina tem sofrido mudanças notáveis em todos os aspectos. A cidade cresceu. Nascida com a igreja do Amparo - edificada entre dois rios - o Parnaíba e o Poti, a cidade atravessou o Poti, onde sugiram novos bairros, e caminha nesse sentido, acompanhando o asfalto, no rumo de outra cidade, Altos, a uns 40 quilômetros de distância. Em cento e vinte anos de existência, naturalmente que surgiram bairros por todos os cantos e recantos, praças, as ruas ficaram mais compridas para os duzentos e cinqüenta mil viventes. ${ }^{30}$

Pode-se perceber também a presença do Estado, "como indutor da dinâmica urbana”, nas esferas federal, estadual e municipal. No âmbito federal, vale destacar a criação do BNH, em 1964, priorizando, naquele contexto, a habitação como a mais importante política pública, o que levou à construção de inúmeros conjuntos habitacionais e à expansão da malha urbana:

em Teresina, entre os anos de 1966 e 1969, foram construídos cinco conjuntos habitacionais, com destaque para conjunto habitacional do Parque Piauí, com o 
total de 2.294 unidades, na zona Sul, que concentrava a maioria dos conjuntos, com exceção do conjunto Primavera I, localizado na zona Norte. ${ }^{31}$

É nesse quadro que as favelas começam a ganhar destaque em Teresina. A primeira favela a se constituir, e também a que requereu uma atenção especial do poder público, foi a Favela Cohebe: "Os seus primeiros habitantes começaram a se alojar naquela área em 1974 ... Concomitantemente ao crescimento da favela Cohebe, outras foram se constituindo e tornando-se figuras presentes na cena urbana". ${ }^{32}$ Apesar da política habitacional iniciada na década anterior, naquele momento essa questão não mereceu a atenção do poder público, a não ser pela violência policial, usada para a expulsão das pessoas da área ocupada, já que, segundo Antonia Jesuíta de Lima ${ }^{33}$ "o fenômeno favela não era enfrentado como uma questão social, mas de polícia”. Mesmo assim, a atuação do poder público municipal era isolada e fragmentária, não obedecendo a uma orientação de política global, de modo que as intervenções se davam, prioritariamente, na estruturação da malha viária, que a imprensa local noticia:

O Prefeito de Teresina está executando um avançado plano urbanístico, o qual transforma a Capital piauiense numa moderna, evoluída, bela e atrativa cidade. As avenidas Maranhão e Poti, ligadas à Avenida Miguel Rosa, formarão o anel de contorno da cidade e se constituirão, em si mesmas, artérias das mais belas do País.

Uma verba de 3,6 milhões de cruzeiros será aplicada na urbanização de Teresina, segundo projeto do urbanista Alexandre Costa. ${ }^{34}$

A construção do anel viário da cidade, abrindo e asfaltando várias avenidas que vieram descongestionar o trânsito de nossa Capital, preparando-a para se integrar num todo, atraindo os bairros ao Anel Viário recém-construído, foi um projeto de alta visão administrativa, que descortinará o desenvolvimento e a expansão da cidade.

Constituem o elenco do anel viário a pavimentação das avenidas Miguel Rosa, Maranhão e José dos Santos e Silva e trecho da Barão de Castelo Branco. Integrou-se ao sistema viário a conclusão definitiva ao trecho compreendido entre a Avenida Joaquim Ribeiro e BR-316. A pista da Avenida Miguel Rosa foi duplicada, no trecho compreendido entre a Rui Barbosa e a Avenida Frei Serafim..$^{35}$

Sobre o Plano de Desenvolvimento Local Integrado (PDLI), voltado para o planejamento urbano de Teresina, especialistas o avaliaram como inadequado à realidade local, mas com ele surgiu a primeira lei de zoneamento da 
cidade, que não foi aplicada, exceto alguns projetos de infra-estrutura urbana com pequeno implemento na melhoria do padrão de vida na cidade: "A não concretização do Plano, na sua maior parte, trouxe conseqüências drásticas para Teresina, no começo da década de 70, na medida em que a cidade cresceu sem nenhum instrumento regulador do espaço urbano". ${ }^{36}$

Em entrevista concedida ao jornal O Globo, do Rio de Janeiro, Alberto Tavares Silva, governador do Piauí (1971-1975), destaca que recebia o apoio do governo federal para o seu plano de atuação no Estado. Vivia-se ainda a euforia do crescimento econômico, provocada pelo chamado 'milagre brasileiro'. Em nível local, o eixo da política governamental volta-se para dinamizar a economia piauiense, enfatizando-se a integração do território do Piauí ao restante do país. Com base nesse discurso, é construída a rodovia Transpiauí, com a intenção de ligar Parnaíba, no litoral, a Corrente, no extremo sul do Piauí, divisa com a Bahia, sem mencionar seu objetivo, que era permitir a ligação do Piauí a Brasília, pelo interior.

A euforia da conquista da Copa do Mundo em 1970, no auge da ditadura militar, incentivou o governador a construir um estádio de futebol (que recebeu o nome do próprio governador) com capacidade para 70 mil pessoas, à época, metade da população de Teresina. No mesmo governo houve a construção de um hospital com atividades voltadas ao atendimento de pessoas acometidas por doenças infectocontagiosas, percebendo-se, mais uma vez, a atuação do médico-sanitarista que orientou a intervenção do poder público no tecido urbano. ${ }^{37}$

Em Teresina construiu-se um terminal ferroviário que foi chamado de "Pólo Petroquímico de Teresina", passando a receber combustível diretamente do porto de Fortaleza e, posteriormente, do porto de São Luís. Com isso, um trecho das ferrovias implantadas no Piauí ganha uma sobrevida, uma vez que os trens de passageiros começavam a ser desativados.

É perceptível até esse momento que o Estado, como agente construtor e modelador do espaço urbano, ${ }^{38}$ tem uma atuação decisiva na construção do espaço, regulando sua própria ação e a dos outros agentes e ainda consumindo grandes faixas de terra, como aquelas empregadas na construção do estádio de futebol e do terminal ferroviário. Visa-se assim transformar a cidade, dando-lhe o porte de uma metrópole, seguindo-se o modelo aplicado a outras e, na própria capital do Piauí, em outra oportunidade, o da modernização autoritária. Diz Francisco de Assis Soares Gondinho, morador de uma região atingida pela construção da Avenida Miguel Rosa:

Nossa casa ficava na margem do Aterro, no que hoje é a Miguel Rosa na altura da rua Porto, e em 1975, 76, a prefeitura teve que fazer a desocupação das ca- 
sas, quando começou a abertura da Avenida Miguel Rosa. A nossa casa ficava numa vereda da Miguel Rosa pra rua Porto, até sair na Barão de Gurguéia. Aí a prefeitura sentiu a necessidade de fazer o alargamento da rua Porto e aí teve que fazer a desocupação das casas. $E$ as pessoas que ali moravam tiveram que sair, receberam terrenos lá no Buenos Aires, na troca de seus terrenos que ficaram ali, tiveram que sair para a ocupação da rua, e essas pessoas mudaram para lá e nós fomos uma dessas pessoas... ${ }^{39}$

O sr. Francisco de Assis informa que sua família teve de sair. Ele não diz que os representantes do poder público foram discutir, antes disso, a necessidade da construção da Avenida Miguel Rosa. Ele informa apenas que tiveram de "desocupar a casa para fazer o alargamento da rua Porto". As pessoas receberam terrenos na periferia.

As duas praças centrais de Teresina, a Pedro II e a Rio Branco, tiveram, na mesma época, os seus traçados originais modificados sem que os moradores da cidade pudessem discutir tais intervenções. Sobre a Rio Branco, Arimátea Tito Filho diz:

Aqui tens a Praça Rio Branco, o coração comercial da cidade. De manhã, mulatas, morenas, louras casadas e solteiras, brotos, coroas e matronas circunspetas praticam o entra-e-sai, visitando as dezenas de casas comerciais existentes na praça e nas ruas vizinhas. Senhores sisudos, estudantes, gente de todo naipe paqueram, conversam, trocam dedos-de-prosa e contam as últimas sempre com um aumentozinho - o aumentozinho maledicente. Encontro de poetas, de jornalistas, de intelectuais. De tarde, a partir das 16 horas, a movimentação é intensa. De noite, a praça fica deserta, como cidade abandonada de cinema de bandido norte-americano. ${ }^{40}$

Tais reformas se fizeram, como já foi dito, de forma autoritária. As praças, por exemplo, foram totalmente reconstruídas, afetando a relação entre os usuários e o espaço, o qual pode ser transformado em suporte da memória, que, por sua vez, tem relação direta com a memória das pessoas. Mesmo quando o poder público convidava a população a participar do zelo da cidade, o formato soava mais como uma ordem da Coordenação de Planejamento da Prefeitura procurando sensibilizar os moradores, especialmente os residentes na área mais central, a aderir à campanha de embelezamento de Teresina, "trabalho que imprescinde da colaboração dos munícipes nas providências concernentes à restauração de calçadas e muros de imóveis dos proprietários. $\mathrm{O}$ proprietário assim contribuindo estará integrando-se à campanha de melho- 
ria urbanística" ${ }^{41}$ Não há notícias de que a população tenha atendido ao 'apelo' dos dirigentes da cidade no sentido de deixá-la mais bonita.

O Palácio de Karnak, sede do governo, recebeu uma intervenção na sua arquitetura e em seu jardim, assinada por Burle Marx, e a principal avenida de Teresina, a Frei Serafim, teve modificado o desenho da calçada central, com o asfaltamento nas duas pistas de rolamento, antes calçadas com paralelepípedos de cor escura. O asfalto parecia, ao olhar dos administradores, uma 'coisa' moderna, bem como a iluminação diferente da já existente.

Aliás, acerca dessa nova iluminação pública, o comentarista de um jornal local chama a atenção para especificidades das lâmpadas:

A Cepisa iniciou a instalação de novas lâmpadas incandescentes na iluminação pública de Teresina. O destaque da informação está em que as novas lâmpadas, que já estão sendo instaladas pela Cepisa, tiveram fabricação especial, com o filamento reforçado, para maior durabilidade. ${ }^{42}$

Já o cronista Arimátea Tito Filho, em texto sobre a Avenida Frei Serafim, localiza e historiciza o logradouro público:

Por trás da igreja, a avenida espaçosa a que uns dão o nome do frade [Frei Serafim de Catânia], outros dão o nome de Getúlio Vargas. Um avenidão de trânsito intenso. Pedestre nela come fogo para a travessia. De manhã e de tarde por ali passam veículos do mais variado formato. Carros feios e bonitos. Ciclista como praga. Talvez Teresina tenha mais bicicleta do que a capital da Suécia, onde até o rei anda de bicicleta. De noite a movimentação é a mesma - mas um novo quadro surge, a partir das 22 horas: o trottoir. As garotas apresentam-se para o amor, geralmente o amor começa motorizado e há de acabar nos castelos escondidos dentro dos matos que circundam os bairros, como em Brasília. Um paraíso de afeto, esta tranqüila Teresina. ${ }^{43}$

Embora o cronista aparentemente apenas relate práticas e atitudes do cotidiano de um dos logradouros públicos mais bonitos da cidade, termina denunciando alguns aspectos interessantes, como o número de bicicletas que circulavam pela avenida. Esse transporte tinha deixado de ser um bem de luxo para tornar-se um meio de transporte das camadas populares, especialmente dos trabalhadores que precisavam deslocar-se da periferia para o centro da cidade, muito usado também por alunos e filhos de trabalhadores, que não dispunham de recursos para o pagamento diário do transporte coletivo.

Outro aspecto sobre o qual o cronista trata é o da ressignificação dos espaços. A Avenida Frei Serafim, depois que recebeu iluminação com lâmpadas 
de vapor de mercúrio, uma nova passarela central e cobertura asfáltica, transformou-se em ponto de encontro, daí que homens em automóveis por ela circulavam em busca de parceria, de sorte que a cidade é, por excelência, palco das contradições: o poder público empurrou mulheres de vida livre que moravam e trabalhavam na Avenida Miguel Rosa e imediações para a periferia, ${ }^{44}$ longe dos olhares dos visitantes, das senhoras conservadoras e das jovens pudicas, enquanto a principal avenida de Teresina, depois das 22 horas, transformava-se num lugar onde prostitutas e homossexuais buscavam parceiros para encontros amorosos.

Teresina tornou-se um canteiro de obras, pois o período de governo de Alberto Silva (1971-1975) é praticamente o mesmo do prefeito Joel Silva Ribeiro (1971-1974), tido como o responsável pela construção do anel viário da capital e também pela estruturação da malha rodoviária. É igualmente desse período a abertura da Avenida Miguel Rosa, para cuja construção o coordenador de Planejamento da Prefeitura de Teresina informa, em nota oficial, que foram deslocadas para o bairro Poti Velho mais de 270 famílias da área cortada pelo traçado da avenida, "tudo se processando normal ... sem o mais leve incidente". ${ }^{45}$ Todavia, publicou-se uma nota para explicar um incidente:

No trabalho de desobstrução da Avenida Miguel Rosa, que a Prefeitura vem realizando, foi atingido o imóvel de propriedade daquele cidadão [Otoniel Ferreira de Sousa].

O pedido do sr. Otoniel Ferreira era de Cr\$ 16.000,00 (dezesseis mil cruzeiros) e, quando eu teria de emitir meu parecer, que seria concludente no processo, aquele cidadão telefonou-me propondo-me $\mathrm{Cr} \$ 4.000,00$ (quatro mil cruzeiros).

Naturalmente, reagi à tentativa de suborno do Sr. Otoniel, aconselhando-lhe que não mais me procurasse. ${ }^{46}$

É muito grande a possibilidade de o representante da Prefeitura mentir ou omitir sobre as tensões provocadas pela transferência da população, de uma área próxima ao centro comercial da cidade para um bairro onde as enchentes dos rios Parnaíba e Poti freqüentemente atingiam os moradores. Os moradores sempre reagiram, especialmente aqueles cujas casas eram próprias, apesar de aqueles que moravam em barracos cobertos de palha e não possuíam a propriedade da terra por vezes se manifestarem favoravelmente à transferência, em troca de um lote de terra e uma casa, muitas vezes construída de taipa.

Para receber moradores da Miguel Rosa que tiveram suas casas demolidas, a Prefeitura Municipal de Teresina construiu outras casas no loteamento 
chamado Buenos Aires, local muito afastado da área central da cidade e sem nenhuma infra-estrutura, já que não tinha água, energia elétrica nem posto de saúde, e o transporte coletivo era insuficiente. Ademais, a duplicação da pista dessa avenida atingiu pequenos prostíbulos espalhados pela região e as mulheres que ali trabalhavam foram deslocadas para um bairro distante, manifestando preocupação com a sobrevivência, mas lembrando que as casas, dali por diante, lhes pertenciam. Com a intervenção no tecido urbano, o poder público resolvia dois problemas: embelezava a cidade e afastava as prostitutas da sua área mais visível. O discurso médico-sanitarista orientava a limpar a cidade daqueles lugares perigosos à saúde pública, enquanto setores mais conservadores da Igreja católica festejavam o fim dos 'lugares de perdição'.

A senhora Maria do Livramento Rodrigues Rios, uma das mulheres deslocadas para o loteamento Buenos Aires, lembra os momentos que antecederam a mudança:

Aí que tiraram a casinha que nós morava, para fazer a avenida. Aí de lá nos deram esse terreno aqui. Aí quando construíram a Miguel Rosa, foi obrigado nós vim pra cá. A gente recebeu e deu graças a Deus. Muitos aceitaram e muitos não aceitaram. Quem queria vim é porque não tinha morada, viu? Morava de aluguel. ${ }^{47}$

A fala de dona Maria do Livramento não deixa dúvida de que o processo de limpeza da área central de Teresina se fez sem que as pessoas mais pobres tivessem oportunidade de discutir sobre o outro local de moradia. Reações existiram, mas a maioria absoluta desses moradores não possuía condições financeiras para adquirir um lote de terra mais próximo do centro.

Assim, a cidade se moderniza. Marshal Berman ${ }^{48}$ defende que os ideais modernizantes construídos nos países subdesenvolvidos, para se concretizarem, tornam-se rudes, ásperos com aqueles que se contrapõem à sua efetivação, aspecto facilmente perceptível no processo de modernização de Teresina, desde o início do século XX. A cidade, ao ter o espaço urbano modernizado e com maior visibilidade, expulsa os mais pobres para áreas periféricas, sem criar meios para atender às suas demandas, o que não significa necessariamente que os pobres não resistam, até mesmo usando os espaços modernizados.

Berman destaca que, nas intervenções realizadas em cidades de países periféricos, o modernismo emerge do atraso e do subdesenvolvimento. Isso se deu pela primeira vez na Rússia, mais drasticamente em São Petersburgo, no século XIX; com o avanço da modernização que aqui se refere, expandiuse por todo o Terceiro Mundo. Na verdade, o modernismo do subdesenvolvimento é forçado a se construir de fantasmas e de sonhos de modernidade, a se nutrir de uma intimidade e lutar contra miragens. Como a vida da qual 
emerge é forçado a ser estridente, grosseiro e incipiente, e se dobra e se tortura por sua incapacidade de, sozinho, fazer a história, ou lançar as tentativas extravagantes de tomar para si toda a carga da história.

Ele se chicoteia em frenesis de auto-aversão e se preserva apenas através de vastas reservas de auto-ironia, contudo a bizarra realidade de onde nasce esse modernismo e as pressões insuportáveis sob as quais se move e vive - pressões sociais e políticas, bem como espirituais - infundem-lhe uma incandescência desesperada que o modernismo ocidental, tão mais à vontade nesse mundo, jamais conseguirá igualar. ${ }^{49}$

As praças, o jardim do Palácio de Governo e as calçadas centrais da Avenida Frei Serafim foram dotadas, pelo engenheiro Alberto Silva, de fontes de onde saíam jatos d'água movidos por motores elétricos, iluminadas por luzes coloridas, passando esse adorno a fazer parte da paisagem de Teresina, causando um impacto nos moradores da cidade que ainda precisa ser avaliado. Como nos lembra Ítalo Calvino, ${ }^{50}$ "jamais se deve confundir uma cidade com o discurso que a descreve. Contudo, existe uma ligação entre eles”. Pode-se dizer que, no universo das crianças, as fontes luminosas incrementaram-lhes as fantasias, mas entre os adultos que tiveram suas casas demolidas para dar lugar às novas avenidas, é necessário descobrir que papel representaram essas fontes luminosas e também a nova iluminação dos principais corredores da cidade.

\section{NOTAS}

${ }^{1}$ Desejo do governador Alberto Tavares da Silva (1971-1975), em entrevista concedida ao jornal O Dia em 15 mar. 1971, p.1.

${ }^{2}$ PERRONE-MOISÉS, Leila. José Castelo: um cronista fantástico. São Paulo: Global, 2003. p.7.

${ }^{3}$ COELHO, Eduardo. Manuel Bandeira. São Paulo: Global, 2003. p.8.

${ }^{4}$ Há pelo menos dois anos, com apoio do $\mathrm{CNPq}$, vem sendo desenvolvida pesquisa sobre a cidade de Teresina, com a qual se pretende desfraldar as múltiplas cidades contidas na capital piauiense e, ao mesmo tempo, entender o tenso processo de modernização autoritária que a cidade viveu especialmente entre as décadas de 1950 e 1970. O trabalho prevê o tratamento de um largo leque de fontes, mas o interesse maior é pelas fontes hemerográficas, existentes no Arquivo Público do Piauí - Casa Anísio Brito. As fontes orais e documentos oficiais, bem como as imagens registradas por repórteres fotográficos, também fazem parte dos indícios que ajudaram na tentativa de captura daquele tempo.

${ }^{5}$ Em Orfeu extático na metrópole: São Paulo — sociedade e cultura nos frementes anos 20, lançado pela Companhia das Letras, Sevcenko se apoiou em cronistas que discutiram a ci- 
dade no período estudado. Chalhoub em algumas oportunidades se apoiou em Machado de Assis para discutir a cidade do Rio de Janeiro da segunda metade do século XIX.

${ }^{6}$ Em algumas oportunidades se apoiou em Machado ode Assis para discutir a cidade do Rio de Janeiro da segunda metade do século XIX.

${ }^{7}$ BARROS, Helvídio Nunes de. Tempos de política. Teresina: Alínea Produções, 1996. p.15.

${ }^{8}$ DUARTE, Fonseca. Estado do Piauí, Teresina, 25 jan. 1959. p.2.

${ }^{9}$ Trata-se de Francisco das Chagas Rodrigues (1959-1962), que pertencia aos quadros do PTB.

${ }^{10}$ José Pinheiro de Carvalho era jornalista e morava no Rio de Janeiro, onde angariou alguma notoriedade e de onde desenvolvia campanhas publicitárias a favor do estado em que nascera.

${ }^{11}$ ROLNIK, Raquel. O que é cidade. São Paulo: Brasiliense, 1985.

12 “Teresina”. Estado do Piauí, 18 abr. 1963, n.535, p.4.

${ }^{13}$ Ibidem.

${ }^{14}$ BACELLAR, Olavo Ivanhoé de Brito. Carta Cepro, Teresina, v.15, n.1, jan.-jun., 1994, p.75-98.

${ }^{15}$ PREFEITURA Municipal de Teresina. Nota oficial. Estado do Piauí, 5 mar. 1959, p.3.

${ }^{16}$ A data oficial de transferência da antiga capital da Província do Piauí, a cidade de Oeiras, para Teresina é 15 de agosto de 1852 .

17 “A Praça Saraiva”. Estado do Piauí, 20 maio 1971, p.3.

${ }^{18}$ Estado do Piauí, 20 jun. 1963, p.1.

${ }^{19}$ Ibidem.

${ }^{20}$ MENDES, Simplício de Sousa. Dinamismo. O Dia, 20 jan. 1964, p.1.

${ }^{21}$ FAÇANHA, Antonio Cardoso. Desmistificando a geografia: espaço, tempo e imagens. Teresina: Ed. UFPI, p.180.

${ }^{22}$ SILVA, Francisco Cunha e. Perspectivas de maior progresso. Estado do Piauí, 27 jun. 1963, p.1.

23 “Aeroporto de Teresina”. Estado do Piauí, 25 jun. 1961, p.3.

${ }^{24}$ LIMA, Iracilde Maria de Moura Fé. Teresina urbanização e meio ambiente. Scientia et spes, Revista do Instituto Camilo Filho, Teresina, v.1, n.2, p.181-206, jun. 2002.

${ }^{25}$ TITO FILHO, Arimatéa. Teresina meu amor. Teresina: Comepi, 1973. p.51.

26 "Decreto n. 68.631, de 19 maio 1971, aprova o estatuto da Fundação Universidade Federal do Piauí".

27 “Aumento de Renda per capita do Piauí é o objetivo do Governo Alberto Silva”. Estado do Piauí, 15 jul. 1971, p.3.

${ }^{28}$ Ibidem.

29 “Fábrica de Coca-Cola”. Estado do Piauí, 27 maio 1971, p.1.

${ }^{30}$ TITO FILHO, Arimatéa, op. cit., p.35.

${ }^{31}$ FAÇANHA, Antonio Cardoso, op. cit., p.184. 
${ }^{32}$ LIMA, Antonia Jesuíta de. Favela Cohebe: uma história da luta por habitação popular. Teresina: Ed. UFPI, 1990. p.25.

${ }^{33}$ Ibidem.

${ }^{34}$ Estado do Piauí, 18 jul. 1971, p.3.

${ }^{35}$ Estado do Piauí, 15 maio 1971, p.4.

${ }^{36}$ Ibidem.

${ }^{37}$ Sobre tecido urbano, ver PANERAI, Philippe. Análise urbana. Brasília: Ed. UnB, 2006.

${ }^{38}$ CORREA, Roberto Lobato. O espaço urbano. 4.ed. São Paulo: Ática, 2002.

${ }^{39}$ GONDINHO, Francisco de Assis Soares. Entrevista concedida a Laécio Barros Dias e Regianny Lima Monte. Teresina, 15 set. 2006.

${ }^{40}$ TITO FILHO, Arimatéa, op. cit., p.57.

${ }^{41}$ Estado do Piauí, 11 maio 1971, p.3.

${ }_{42}$ "Informativo da Cepisa”. Estado do Piauí, 1 abr. 1971, p.1.

${ }^{43}$ TITO FILHO, Arimatéa, op. cit., p.59.

${ }^{44}$ Sobre periferia ver ULTRAMARI, Clovis; MOURA, Rosa. O que é periferia urbana. São Paulo: Brasiliense, 1996.

${ }^{45}$ PREFEITURA Municipal de Teresina. Nota Oficial. Estado do Piauí, 12 dez. 1970, p.1.

${ }^{46}$ Ibidem.

${ }^{47}$ RIOS, Maria do Livramento Rodrigues. Entrevista concedida a Laécio Barros Dias e Regianny Lima Monte. Teresina, 10 nov. 2006.

${ }^{48}$ BERMAN, Marshal Tudo que é sólido desmancha no ar. (Trad. Carlos Felipe Moisés; Ana Narua I. Ioriatti). São Paulo: Companhia das Letras, 1986.

${ }^{49}$ PREFEITURA Municipal de Teresina. Nota Oficial. Estado do Piauí, 12 dez 1970, p.1.

${ }^{50}$ CALVINO, Ítalo. As cidades invisíveis. (Trad. Diogo Mainardi). São Paulo: Companhia das Letras, 1990. 